\begin{tabular}{l|l|l|l} 
& $=$ & $7^{\text {th }}$ CONGIC & Blucher Design Proceedings \\
$7^{\text {th }}$ CIDI & $\begin{array}{l}7^{\text {th }} \text { Information Design } \\
\text { International Conference }\end{array}$ & $\begin{array}{l}7^{\text {th }} \text { Information Design } \\
\text { Student Conference }\end{array}$ & $\begin{array}{l}\text { Setembro, 2015 }- \text { num. 2, vol.2 } \\
\text { proceedings.blucher.com.br }\end{array}$
\end{tabular}

\title{
A adaptação de infográficos jornalísticos: a relação entre as versões on-line e impressa
}

The adaptation of journalistic infographics: the relationship between on-line and printed versions

\author{
Ricardo Cunha Lima, Rafael de Castro Andrade, André Monat, Carla Galvão Spinillo
}

layout, infografia, linguagem gráfica, on-line, impresso

\begin{abstract}
Neste artigo, realizamos uma avaliação crítica da relação entre design on-line e impresso, com foco na linguagem gráfica da infografia de jornal. Grande parte do trabalho feito nessa área consiste na adaptação da infografia do jornal impresso para versões on-line. O problema dessas adaptações é que, nas versões on-line, ocorrem perdas na estrutura e na estratégia de leitura, limitando a experiência do leitor a um texto linear. Para entender isso, comparamos infográficos impressos com suas versões digitais, através da análise do layout e dos efeitos sobre a carga cognitiva. Em uma época em que o conhecimento de programação de computadores parece ser crucial para o design editorial, refletimos sobre a importância do layout, que é a principal estrutura de comunicação em design para ajudar os leitores a acessar e compreender a informação.
\end{abstract}

layout, infographics, graphic language, on-line, print

In this article we make a critical assessment of the relation between online and print design, focusing on the graphic language of newspaper infographics. A lot of the work done in this area consists in adapting print newspaper infographics to online versions. The problem with many of these adaptations is that there are losses in reading strategy and structure of their online versions, offering readers a mainly linear reading experience. To understand this fact, we compare print infographics and their digital versions through the analysis of layout and cognitive load. In a time when the knowledge of computer programming seems to be crucial to editorial design, we reflect on the importance of layout, which is the principle design structure to help readers access and understand information.

\section{Introdução}

O design de jornais, como campo do conhecimento, só passou a ser valorizado recentemente graças aos avanços tecnológicos em jornalismo. Uma das consequências da ampliação do papel do design foi a consciência da necessidade de haver uma estrutura tipográfica mais eficaz no layout dos jornais. A fórmula tradicional de layout para jornal, com texto e imagens pictóricas apresentadas isoladamente, não era suficiente para explicar fatos e processos complexos ao público em geral, tornando necessárias estruturas que integrassem os elementos gráficos. 
Paralelamente, os infográficos também estavam se desenvolvendo, passando de simples diagramas para narrativas gráficas não-lineares complexas. A inovação tecnológica foi um fator importante na inclusão de infográficos no design de notícias. No surgimento do jornal norte-americano USA Today, em 1982, foi adotado o processo de impressão em quatro cores, uma vez que havia demanda do público leitor por imagens coloridas e infográficos (MORAES, 2013). Nos últimos anos, o desenvolvimento da tecnologia da informação on-line tem sido um dos principais responsáveis pela inovação na infografia. Com a atual disseminação e facilidade de acesso à informação, os infográficos têm ajudado os leitores a compreender e processar informações de forma rápida, e isso ocorre, em parte, pelos meios variados de simbolização disponíveis em um infográfico.

Michael Twyman $(1979,1985)$ propôs a idéia de que a linguagem gráfica é composta de diferentes modos de simbolização: o pictórico, o verbal e o esquemático. Infográficos integram essas modalidades através da estrutura de layout não-linear e, com as possibilidades do jornalismo on-line, o uso de recursos sonoros tem oferecido novas possibilidades para a linguagem gráfica.

Como a infografia jornalística não é uma forma tradicional de iconografia como a ilustração, ela é mais adaptável a novos contextos de comunicação (LIMA, 2009). A infografia é concebida como uma espécie de matéria jornalística, em que texto e iconografia são interdependentes (LIMA, 2009). Nesse contexto, ao contrário do jornalismo tradicional, o texto escrito não é necessariamente a fonte primária de informação. Texto e iconografia se integram em uma estrutura gráfica em que a estratégia de leitura pode desenvolver-se de forma nãolinear, ou seja, o leitor pode escolher a ordem em que ele lê.

Neste artigo, vamos apontar alguns dos problemas enfrentados quando se adapta a infografia impressa para os jornais on-line. Em muitos casos, a principal estratégia dos infográficos adaptados é o uso da narrativa sequencial: o infográfico é dividido em slides que podem ser acessados um de cada vez. O problema dessa estratégia é condicionar o processo de leitura, criando uma noção limitada de narrativa, com opções restritas de interação. Para entender esse processo, discutimos a relevância do layout na teoria da linguagem gráfica proposta por Rob Waller $(1985,2012)$ e o problema da carga cognitiva na experiência de aprendizagem a partir do trabalho de Sweller et al. (1998) e Mayer (2005).

\section{Layout da página}

Rob Waller (2012) discute os problemas que os designers gráficos têm enfrentado com a transição para plataformas on-line e como o layout tem sido afetado neste processo. Waller foi influenciado por Michael Twyman (1979), que propôs que a página é diagramática, o que significa que os leitores compreendem o texto não só como palavras, mas como uma estrutura composta por diferentes elementos de linguagem gráfica. Waller (1985) sugere que a estrutura linear de um livro tradicional tende a ser a prosa. No entanto, essa modalidade gráfica de discurso pode apresentar problemas de comunicação para certos tipos de informação e contextos. Os textos científicos, embora sejam valorizados pela sua precisão, não são o meio ideal para facilitar a compreensão do leitor. Jornais e revistas talvez sejam padrões mais adequados para este fim, pois são projetados levando em conta a estrutura gráfica do conteúdo. Outros bons exemplos de textos que reconhecem a necessidade de clarificar o seu conteúdo graficamente são os livros de referência e manuais técnicos (Waller, 1985:107).

Para satisfazer essas variadas estratégias de leitura, Waller (idem) propõe o conceito de texto como diagrama, ou seja, a estrutura de texto não-linear com qualidade diagramática. Quando o texto é colocado sob a forma de diagrama, a estrutura torna-se mais acessível à leitura menos linear, permitindo que os leitores possam escolher e criar suas próprias estratégias de leitura. Sendo assim, esses textos têm várias colunas e malhas tipográficas (grids) complexas. O foco da análise de Waller é a linearidade dos textos tipográficos (linguagem gráfica

Anais [Oral] do 7º Congresso Internacional de Design da Informação | CIDI 2015

Proceedings [Oral] of the 7th Information Design International Conference / IDIC 2015 
verbal) e sua estrutura. No entanto, o autor não negligencia o papel das imagens pictóricas no processo, pois a estrutura diagramática possibilita uma maior integração de conteúdo pictórico e tipográfico. Como coloca Michael Twyman (1985), o problema da linguagem pictórica é que ela não segue uma gramática bem definida, como é o caso das palavras.

A estrutura de diagrama talvez seja a chave para se compreender a configuração de um infográfico (LIMA, 2009). Infográficos são, em sua essência, diagramas na forma como dispõem elementos pictóricos, esquemáticos e verbais em um layout. Logo, os diagramas e infográficos são caracteristicamente estruturas multimodais, pela variedade de recursos gráficos disponíveis. Tais estruturas são concebidas com a estratégia de leitura não-linear em mente, proporcionando maior liberdade de leitura. Cada infográfico é organizado de acordo com certas regras de uso compatíveis com o seu gênero, como Waller (2012) aponta:

O layout gráfico de tais gêneros contém de fato regras de affordance para seu uso: layouts interessantes e títulos grandes convidam os leitores de revistas a folhear a mesma; o layout ordenado de um manual de usuário convida à leitura sistemática, fazendo referência a uma tarefa fora do texto por meio de diagramas (Waller, 2012:13, tradução nossa).

Waller (2012) propõe que os leitores sabem (ou descobrem) como ler um determinado tipo de documento dependendo das estruturas de acesso (as "regras de uso") do seu gênero. Um artigo de jornal impresso não é lido da mesma maneira que o seu equivalente na internet. Isso se deve, em parte, a uma questão tecnológica: o meio digital e o impresso têm diferentes "naturezas" e, portanto, devem ter configurações diferentes de layout. O que Waller aponta é que, ao adaptar o artigo de jornal impresso para versões on-line, ocorrem perdas na estratégia e estrutura de leitura. Em sua maioria, os textos on-line tendem a ser mais restritos, apresentados em colunas simples, oferecendo pouca variação na estrutura do layout. Se comparado com os seus similares impressos, os textos on-line têm menos possibilidades de interação entre o leitor e o texto, oferecendo uma experiência de leitura predominantemente linear, o que é irônico, porque a não-linearidade é considerada uma das principais características do ambiente on-line.

Essa adaptação pode ser comparada à transição dos manuscritos medievais para o livro impresso. As iluminuras medievais, por causa de seus métodos de produção, ofereciam uma estreita integração entre os conteúdos gráficos pictóricos e verbais. O mesmo já não pode ser dito do livro impresso. Tipografia e iconografia foram separados com a invenção do tipo móvel. Só mais tarde, através do desenvolvimento de novos métodos de impressão e meios de comunicação de massa, texto e imagens pictóricas foram integrados novamente.

A forma como um leitor compreende um gênero de documentos on-line é determinada, de muitas maneiras, por paradigmas moldados por gêneros mais antigos. Muitos documentos on-line têm suas estruturas de acesso determinadas originalmente pelo impresso. E como Waller (2012) menciona, cada nova tecnologia passa por um período de adaptação, mas o novo meio não torna os antigos completamente extintos.

Figura 1: Uma comparação entre as versões on-line e impressa de uma notícia do jornal Folha de São Paulo. Como podemos ver, a variada de estrutura de layout da versão impressa (à direita) é reduzida a um texto linear uma coluna sem o auxílio de ilustração (à esquerda).

Anais [Oral] do 7ํㅡㄹ Congresso Internacional de Design da Informação | CIDI 2015 

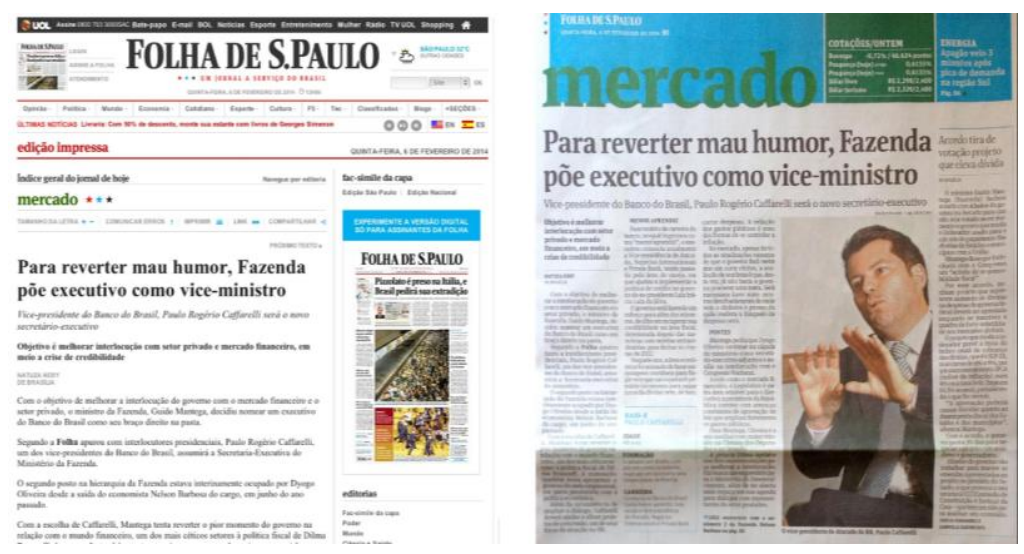

\section{Teoria cognitiva de aprendizagem multimídia e infográficos}

$\mathrm{Na}$ maioria das adaptações de artigos jornalísticos on-line e infográficos on-line, grande parte da estrutura de layout é perdida, comprometendo o conteúdo gráfico proposto originalmente. Para entender melhor essas "perdas", podemos olhar a partir do ponto de vista da psicologia cognitiva. Alguns estudos dessa área investigam como os indivíduos aprendem através de materiais multimídia, usando diferentes modos de apresentação. Um dos estudos citados recorrentemente é a teoria cognitiva de aprendizagem multimídia (TCAM), proposta por Mayer (2002, 2005), em que são propostas sugestões para o desenvolvimento de materiais de aprendizagem multimídia visando um maior nível de aprendizado. O termo multimídia é geralmente usado para se referir a usos variados de mídia (vídeo, música, animação, etc.), mas, para Mayer, o termo está relacionado com a multimodalidade, ou seja, com o conjunto de modos diferentes em que a informação é apresentada.

Mayer baseia sua teoria em três pressupostos:

1. As informações visual e verbal são processadas em diferentes canais - proposto com base nas teorias de Baddley (1974) e Paivio (1986);

2. Cada canal tem uma capacidade limitada de processamento de informação que se origina a partir da carga cognitiva - proposto com base na teoria da carga cognitiva de Sweller et al. (1998).

3. O tratamento das informações em diferentes canais promove ativamente a construção de representações mentais coerentes - proposto com base na teoria de processamento ativo de Wittrock e no modelo SOI, do próprio Mayer (1996).

Estes pressupostos propõem uma melhor utilização dos canais visuais e verbais, adaptando os recursos de carga cognitiva, o que resulta em um processo de aprendizagem mais significativo. A carga cognitiva está ligada diretamente à capacidade de processamento de informação da memória corrente (ou memória de trabalho). De acordo com Sweller et. al (1998), existem três tipos de carga: carga intrínseca, carga irrelevante e carga relevante. Para uma experiência de aprendizagem significativa, as cargas intrínseca e irrelevante devem ser mínimas, para que os recursos cognitivos estejam dedicados à carga relevante, à qual está ligada o processo de construção da aprendizagem.

Para Sweller, a carga intrínseca está relacionada à complexidade da informação. $O$ número de relações entre seus componentes define essa complexidade. Certos tipos de informações são mais complexas. Por exemplo, a aprendizagem de uma gramática estrangeira é, inevitavelmente, mais complexa do que aprender um novo vocabulário, ou seja, a tradução de palavras individuais. Porém, cada leitor percebe a complexidade de um modo diferente. Leitores 
com conhecimento prévio sobre determinada informação podem julgá-la pouco complexa, já outros que não tenham um conhecimento prévio formado podem julgar a mesma informação complexa demais. Desse modo, não é possível reduzir a carga cognitiva intrínseca diretamente sem prejudicar um tipo de leitor. A solução encontrada pelos autores é particionar a informação. Assim, o leitor só tem que compreender parte das informações de cada vez, sem cobrir toda a complexidade de uma só vez. Dessa forma, o leitor pode experimentar a carga intrínseca gradualmente.

Uma vez que a carga intrínseca não pode ser reduzida diretamente, Mayer, com a TCAM, foca nas outras duas cargas, buscando minimizar a carga irrelevante e promover a carga relevante. A carga irrelevante é proveniente da atividade mental gerada pelos materiais de multimídia, e não está diretamente relacionada à aprendizagem. Um exemplo seria um bloco de texto e uma imagem que são complementares, mas que estão dispostos de forma que não há uma correlação clara entre eles. Descobrir essa correlação entre texto e imagem emprega um esforço cognitivo que poderia ser utilizado para compreender o conteúdo do material. O design deficitário desse layout produz uma quantidade maior de carga cognitiva irrelevante. No entanto, quando o layout favorece a compreensão e facilita as relações que o leitor pode ter com o conteúdo, ocorre uma promoção da carga cognitiva relevante.

A partir dessa perspectiva, um infográfico pode ser percebido como um material complexo, dado o número elevado de relações possíveis entre seus elementos. No entanto, algumas características comuns de infográficos atendem às estratégias recomendadas pela TCAM para promover o aprendizado, como, por exemplo, o princípio de multimídia e o princípio de contiguidade.

Mayer (2005) sugere, com o princípio de multimídia, que as explicações que usam imagem e texto promovem uma aprendizagem mais profunda. Essa relação entre imagem e texto é uma característica fundamental da infografia, encontrada em muitas definições de infográficos (Pablos, 1999; Rajamanickam, 2005; Colle, 2004; Teixeira, 2010). Já no princípio da contiguidade, o autor argumenta que elementos multimídia devem estar espacialmente próximos de modo a minimizar uma carga irrelevante.

Waller (2012) nos lembra que, no ensino do design, a "sintaxe visual da página" é entendida por meio de princípios perceptuais oriundos da Gestalt. Esses princípios são independentes de um conteúdo específico e são compatíveis com o princípio da contiguidade proposto por Mayer (2005). Eles são geralmente conhecidos como o "princípio da proximidade", em que elementos que estão fisicamente próximos na página são relacionados de alguma forma, e o "princípio de similaridade", em que elementos que parecem semelhantes são membros da mesma categoria" (Waller, 2012: 11). Podemos observar que é amplamente aceito pelos designers que a contiguidade da forma ajuda os leitores a entender as relações gráficas e a distinguir categorias. Em infográficos, há uma integração íntima de elementos em seu layout, o que melhora o processo de aprendizagem do leitor e minimiza a carga cognitiva irrelevante.

Cabe ressaltar que o âmbito de pesquisa de Mayer se propõe a observar materiais de aprendizagem, não fazendo parte do seu escopo examinar a complexidade do design de documentos e de notícias. Nesse sentido, Waller (2012) parece se aproximar, com uma maior propriedade, da questão da disposição dos elementos no espaço e do seu papel desempenhado na contiguidade.

\section{Análise e conclusão}

A seguir é apresentada uma breve análise do infográfico "Tapuiassauro, o novo dinossauro do Brasil", publicado em ambas as versões impressa e on-line pelo jornal brasileiro O Estado de São Paulo. Cabe ressaltar que, em 2011, a versão on-line desse infográfico recebeu a medalha de ouro na categoria de gráficos on-line do Malofiej, o mais importante prêmio internacional da

Anais [Oral] do 7º Congresso Internacional de Design da Informação | CIDI 2015

Proceedings [Oral] of the 7th Information Design International Conference / IDIC 2015 
área. O infográfico fornece informações sobre a descoberta paleontológica do dinossauro Tapuiassauro, bem como a representação pictórica do dinossauro e detalhes dos fósseis encontrados.

Figura 2: Infográfico "Tapuiassauro, o novo dinossauro do Brasil" para a versão impressa do jornal O Estado de São Paulo. Design: Glauco Lara.

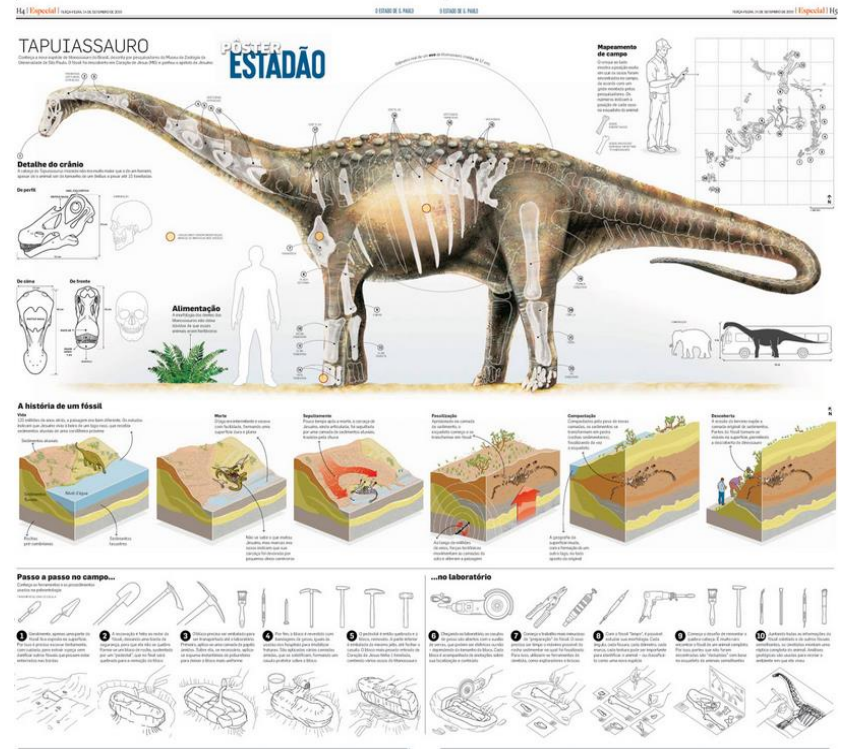

O infográfico impresso foi publicado em uma página dupla (formato standart). conteúdo apresenta-se estruturalmente dividido em três partes principais:

1. Um quadro descritivo dominante do dinossauro, com subitens que detalham a descrição principal.

2. "A história do fóssil", uma representação sequencial da fossilização do dinossauro.

3. "Passo-a-passo da escavação", um inventário dos instrumentos e sequência que descreve os procedimentos em uma escavação paleontológica.

O infográfico impresso permite ao leitor uma noção do todo, o que lhe possibilita decidir suas próprias estratégias de leitura e criar relações entre os blocos de informação. No "passo-apasso da escavação", diferentes categorias de informação são apresentadas em conjunto, em uma estrutura semelhante a uma tabela, permitindo comparações entre os ossos do esqueleto, as ferramentas e os estágios de fossilização.

A versão on-line foi construída usando o Adobe Flash e está dividida em quatro telas que podem ser acessadas através de abas de controle de seleção de conteúdo. Essas abas formam 
uma sequência, como capítulos: 1. "Tapuiassauro", 2. "dinossauros no Brasil", 3. "uma história do fóssil" 4."passo a passo". O controle de seleção de conteúdo pode sugerir uma sequência, mas não é condicionado pela mesma (MIRANDA, 2013), pois, esse tipo de controle permite que o leitor escolha a ordem de leitura pelos temas de cada capítulo.

A primeira tela (Figura 3) mostra a imagem dominante do dinossauro com os subitens presentes na versão impressa do infográfico. No entanto, a versão on-line oferece objetos interativos para revelar o esqueleto. Ao passar o cursor sobre o dinossauro, é possível fazer um raio-x, revelando os ossos do esqueleto, com uma "lupa". Enquanto o leitor verifica o dinossauro, no mapa acima ele pode ver onde esse osso foi localizado na planta da escavação. Essa interação proporciona uma observação direta dos elementos, mas, em relação à versão impressa, permanece compartimentada e sem oferecer uma visão geral do layout.

Figura 3: "Tapuiassauro", primeira tela da versão on-line do

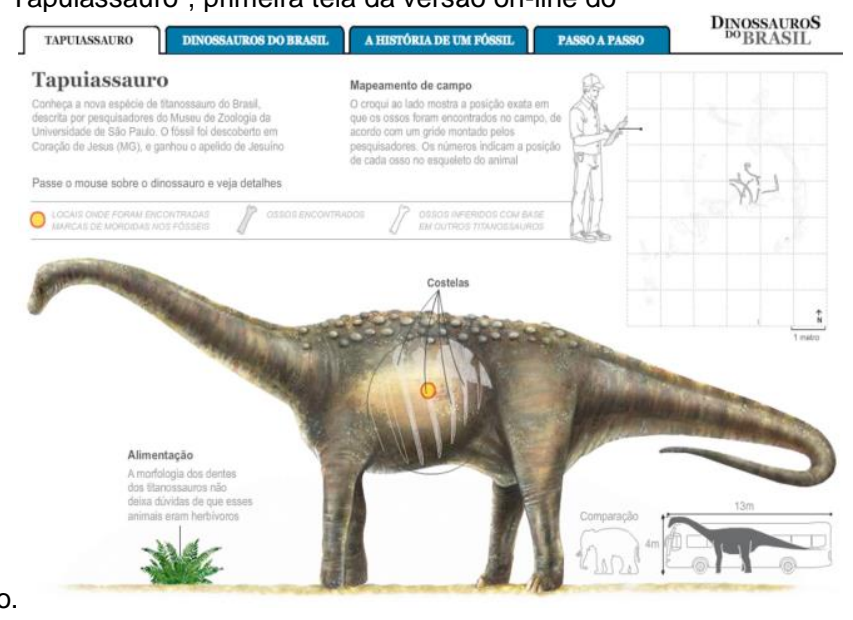

infográfico.

A segunda tela, "dinossauros no Brasil" (Figura 4), permite uma comparação da escala da criatura em relação a outros dinossauros encontrados no país. Ao movimentar o cursor na tela, o leitor pode selecionar um dinossauro e localizar onde ele foi encontrado no mapa do Brasil, e o período de sua existência. Esta seção não está presente no infográfico impresso, porque a mídia on-line tem, geralmente, mais espaço disponível para oferecer conteúdo, não tendo as limitações da página do formato impresso.

Figura 4: "Os dinossauros no Brasil", segunda tela da versão on-line

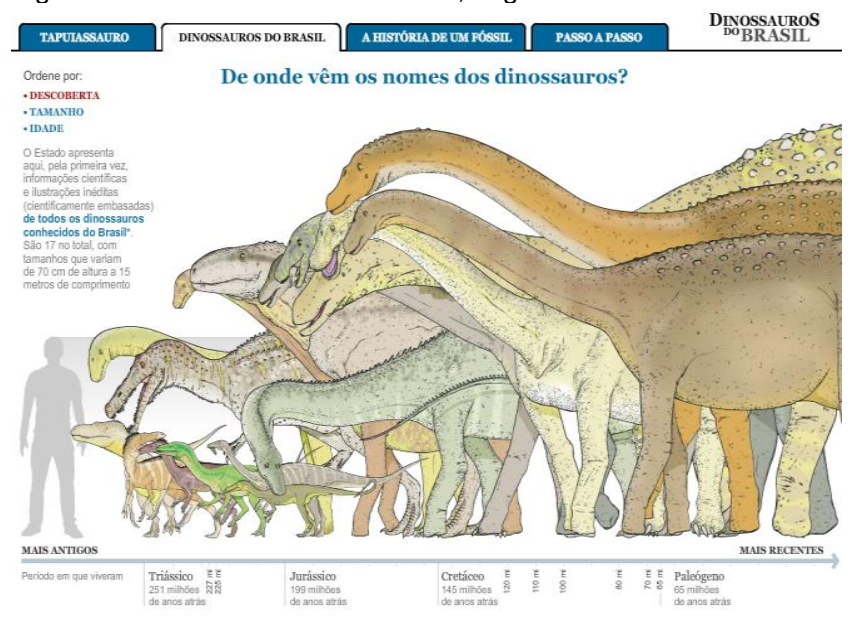

Anais [Oral] do 7º Congresso Internacional de Design da Informação | CIDI 2015

Proceedings [Oral] of the 7th Information Design International Conference / IDIC 2015 
A terceira tela (Figura 5), apresenta um passo a passo da fossilização do dinossauro em slides segmentados. O leitor pode avançar e voltar entre os slides através do controle de narrativa linear (MIRANDA, 2013).

Figura 5: "A história do fóssil", terceira tela da versão on-line
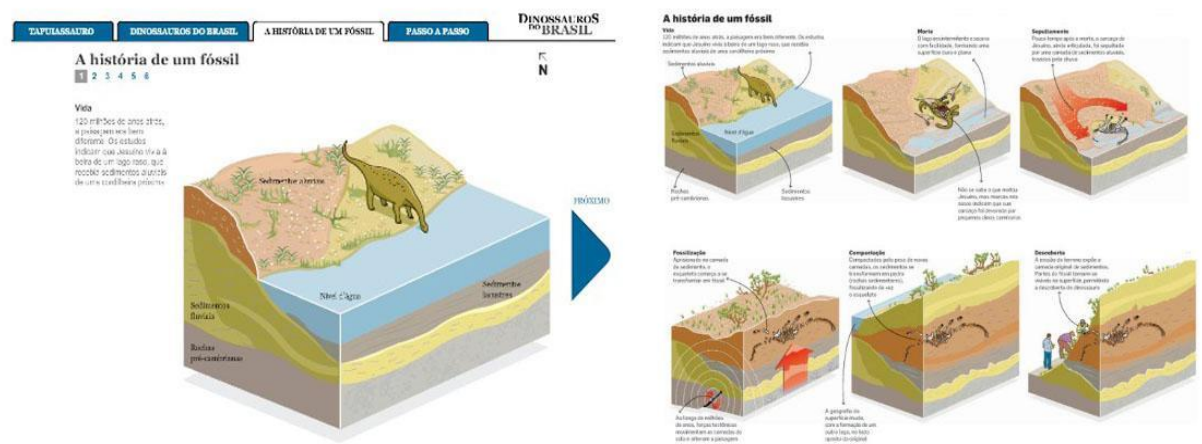

A quarta tela (Figura 6) tem o mesmo inventário de instrumentos e procedimentos presentes na versão impressa. No entanto, o leitor não pode ver todos eles de uma vez, porque esses estão divididos em duas telas, uma para o trabalho de campo e outro para o trabalho de laboratório.

Figura 6. "Passo a passo", quarta tela da versão on-line

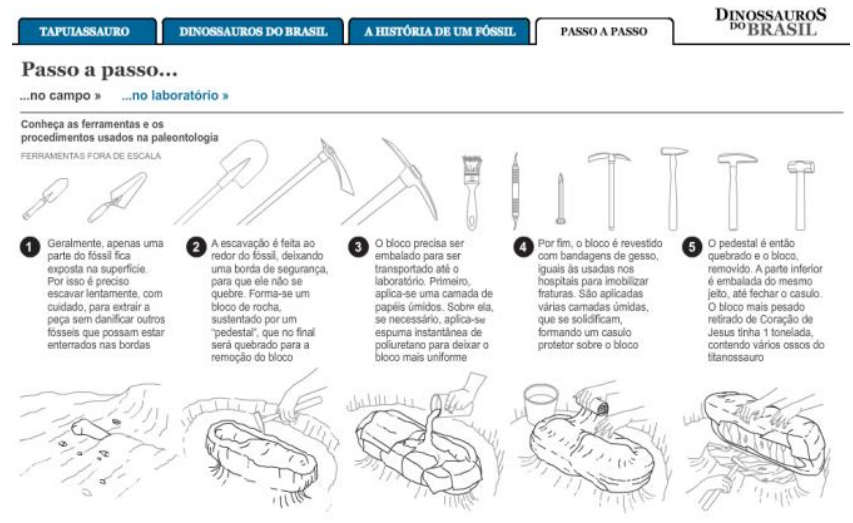

Alguns tipos de controles simples parecem condicionar a leitura, como a seleção de conteúdo e o controle de narrativa linear. A estrutura de leitura não-linear é uma das principais características do infográfico. Ao se adaptar o infográfico limitando a não-linearidade na versão on-line, ocorre a restrição da possibilidade de os leitores navegarem entre os blocos de informações do infográfico, e de criarem a sua própria estratégia de leitura.

Na sequência de slides "uma história do fóssil" (fig. 5), embora o processo de leitura seja fragmentado em blocos de informação, o leitor que quiser fazer uma comparação entre os estágios de fossilização precisa ver cada um individualmente. Essa estrutura quebra a contiguidade entre as diferentes fases e sobrecarrega o leitor, pois nesse caso ele precisa memorizar a fase anterior para relacioná-la com a próxima, gerando uma grande quantidade de carga irrelevante. Isso não ocorre na versão impressa, em que é oferecido um panorama completo da sequência de fossilização.

No exemplo em questão, o uso de controles de narrativa linear e de conteúdo parece limitar as possibilidades de uma melhor compreensão do conteúdo, em parte porque se trata de uma adaptação entre mídias. Há elementos que parecem ter sido escolhidos não para atender 
às demandas de conteúdo informativo, mas para resolver problemas de adaptação entre mídia digital e impressa.

Infográficos publicados em sites de notícias brasileiros tendem a utilizar formas simples de interação, como a seleção de conteúdo e controles lineares de narrativa. Esses recursos interativos quebram o infográfico em partes menores, como vimos no infográfico "Tapuiassauro". Isso pode parecer um benefício, uma vez que minimizaria os efeitos da carga intrínseca proposta por Sweller. No entanto, como Waller (2012) propõe, o leitor costuma estar familiarizado com as regras de uso inerentes a cada gênero editorial. Logo, a variedade de recursos gráficos e a nãolinearidade são pontos positivos. O leitor é convidado a explorar e fazer comparações entre os recursos informacionais do infográfico; ele espera a complexidade de leitura e está pré-disposto a encará-la.

Na versão on-line do infográfico "Tapuiassauro", a maior perda está na ausência de contiguidade entre as diferentes partes que estruturam o layout. Podemos identificar a riqueza da complexidade do layout de um infográfico nas relações entre os elementos multimodais.

Apesar da tendência de se utilizar estratégias de leitura linear em publicações on-line, é comum identificar alguns exemplos que utilizam recursos animados e interativos, rompendo com a linearidade mencionada.

A prática generalizada de adaptação de conteúdo impresso para on-line reflete a atual transição, enfrentada pelo mercado editorial, em que os impressos tem sido substituídos por conteúdo on-line. No entanto, para lidar com essa mudança de paradigmas, as soluções não virão necessariamente dos avanços na tecnologia. Os jornais precisam investir em equipes que possam experimentar novas estratégias, a fim de minimizar os problemas da linguagem gráfica on-line.

Em uma época em que o conhecimento de programação de computadores parece ser crucial para o design editorial, devemos refletir sobre o que é esperado de um designer.

Acreditamos que o foco deve continuar a ser no layout, a principal estrutura de comunicação em design, que auxilia os leitores a compreender e ter acesso à informação.

\section{Referências}

BADDELEY, A. D. 1986. Working Memory. Oxford, England: Oxford University Press.

COLLE, R. 2004. Infografía: tipologías. In: Revista Latina de Comunicación Social. ㄲo 58. Disponível em: http://www.ull.es/publicaciones/latina/latinaart660.pdf

LIMA, R. C. 2009. Análise da infografia jornalística. Dissertação (Mestrado) - Universidade do Estado do Rio de Janeiro, Escola Superior de Desenho Industrial, Rio de Janeiro.

MAYER, R. E. 1996. Learning strategies for making sense out of expository text: The SOI model for guiding three cognitive processes in knowledge construction. Educational Psychology Review, v. 8, p. 357-371.

MAYER, R. E. 2002. Cognitive Theory and the Design of Multimedia Instruction: An Example of the Two-Way Street Between Cognition and Instruction. New Directions for Teaching and Learning. n. 89.

MAYER. R. E. 2005. Cognitive Theory of Multimedia Learning. The Cambridge Handbook of Multimedia Learning. Cambridge University Press.

MIRANDA, F. 2013. Animação e interação na infografia jornalística: Uma abordagem do Design da Informação. Dissertação (Mestrado). Universidade Federal do Paraná, Curitiba.

MORAES, A. 2013. Infografia - História e Projeto. Blucher, p.90.

Anais [Oral] do 7ํㅡㄹ Congresso Internacional de Design da Informação | CIDI 2015

Proceedings [Oral] of the 7th Information Design International Conference / IDIC 2015 
PABLOS, J. M. 1999. Infoperiodismo: el Periodista como Creador de Infografia. Madri: Síntesis.

PAIVIO, A. 1996. Mental representations: A dual coding approach. Oxford, England: Oxford University Press.

RAJAMANICKAM, V. 2005. Infographics seminar handout. Ahmedabad, Disponível em: http://goo.gl/mlL5p

SWELLLER, J. Merrienboer, J.J.G.; Pass, F. 1998. Cognitive architecture and instructional design. Educational Psychology Review, v. 10, p. 251-295.

TEIXEIRA, T. 2010. Infografia e Jornalismo - Conceitos, análises e perspectivas. EDUFBA.

TWYMAN, M. 1979. A schema for the study of graphic language, in P. A., Kolers, M. E., Wrolstad and $\mathrm{H}$., Bouma (Eds.), Processing of visible language (Vol. 1). New York: Plenum.

TWYMAN, M. 1985. Using pictorial language: a discussion of the dimensions of the problem, in T. D., Duffy and R., Waller (Eds.), Designing usable texts. New York: Academic Press.

WALLER, R. 1985. Text as diagram: using typography to improve access and understanding, in D Jonassen (Ed.), The Technology of Text, Vol. 2, New Jersey: Educational Technology Publications, p. 137-166.

WALLER, R. 2012. Graphic literacies for a digital age: the survival of layout, The Information Society: An International Journal, 28:4, 236-252.

WITTROCK, M.C. 1974. Learning as a generative process. Educational Pyschologist. v. 11, p. 87-95.

\section{Sobre os autores}

Ricardo Cunha Lima, Doutorando, ESDI, Brasil <rclima@gmail.com>

Rafael de Castro Andrade, Mestre, UFPR, Brasil <ancara@gmail.com>

André Soares Monat, PhD, ESDI, Brasil <andresmonat@yahoo.com.br>

Carla Galvão Spinillo, PhD, UFPR, Brasil <cgspin@gmail.com>

Anais [Oral] do $7^{\circ}$ Congresso Internacional de Design da Informação | CIDI 2015

Proceedings [Oral] of the 7th Information Design International Conference / IDIC 2015 